\title{
Use of digital technology in museums: the knowledge construction about art mediated by artificial intelligence
}

\section{SIGRADI2018 TECHNOPOLITICAS \\ xxii congresso da sociedade iberoamericana de gráfica digital 22th conference of the iberoamerican society of digital graphics 07|08|09|novembro|2018 iau usp | são carlos | sp br}

\author{
Diego Enéas Peres Ricca \\ FAU USP | Brazil | diego.ricca.p@gmail.com \\ Dra. Clice de Toledo Sanjar Mazzilli \\ FAU USP | Brazil | clice@usp.br
}

\begin{abstract}
This paper aims to identify usability aspects arising from the interaction of museum visitors with content mediation artifacts that use digital technology - in order to perceive design guidelines aimed at enhancing the visitor's construction of knowledge. This was analyzed by the observation - in an audio and video survey - of fifteen users interacting with artificial intelligence as a guide to the museum experience on the project $A$ Voz da Arte in the Pinacoteca de São Paulo museum.
\end{abstract}

Keywords: Museum; Technology; Artificial Intelligence; Human-Computer Interaction; Activity Theory.

\section{INTRODUÇÃO}

$\mathrm{Na}$ contemporaneidade a tecnologia digital encontra-se cada vez mais presente em variadas formas e espaços. Tal mudança gera impactos políticos, sociais e econômicos e intensifica a necessidade dos museus de se adaptarem a esta nova realidade, sendo esta uma prática que se consolida cada vez mais no Brasil e no mundo (Boelter, 2016). Passar de um museu "tradicional" para um "digital" significa, para os propósitos deste artigo, utilizar tecnologia não apenas em suas obras, como também em artefatos voltados a enriquecer a experiência e potencializar a transmissão de conhecimento aos visitantes. Questiona-se, portanto, o que é apenas entretenimento informativo e o que é propriamente conhecimento proporcionado pela experiência. Tendo em vista que 0 ato de simplesmente digitalizar a mediação de conteúdo não torna automaticamente a experiência de visitação satisfatória, se assume aqui que uma série de elementos projetuais e subjetivos devem ser considerados para que esta seja, de fato, enriquecedora para o usuário.

Pelos motivos acima apontados, este trabalho busca identificar aspectos projetuais relevantes para a construção de conhecimento sobre arte em museus por meio da interação com uso de inteligência artificial. Para isso serão observados problemas e potencialidades advindos da interação de usuários com artefatos tecnológicos digitais mediadores de conteúdo a partir de uma análise da usabilidade da interação do visitante em atividade. Apresenta-se aqui um estudo de caso relativo ao uso de inteligência artificial (IA) em um projeto da Pinacoteca de São Paulo chamado A Voz da Arte. Neste experimento, realizado em parceria com a IBM em 2017, o visitante interage verbalmente com as obras do museu utilizando-se do IBM Watson, um sistema cognitivo de IA que serve como mediador de perguntas dos usuários sobre as obras de arte por meio da tecnologia, sendo, portanto, um guia para a experiência museológica.

Coletou-se aspectos relevantes baseado da observação de usuários em atividade, a partir da experiência de interação com o projeto $A$ Voz da Arte. A coleta de dados se deu por levantamento de áudio e vídeo da interação de quinze visitantes, seguida por entrevistas semiestruturadas com questões relativas a experiência individual. A análise foi fundamentada na interpretação de manifestações - verbais, gestuais e sociais oriundas dos visitantes - com bases teóricas no design centrado no usuário articulado à Teoria da Atividade.

\section{MÉTODO}

\subsection{APRESENTACÃO DO PROJETO A VOZ DA ARTE}

A Pinacoteca de São Paulo, em conjunto com sua patrocinadora IBM, idealizaram a ação $A$ Voz da Arte, possibilitando que o visitante pudesse aprender mais a respeito de sete obras escolhidas do museu por meio de interação com a tecnologia cognitiva do Watson. Tal ação teve início no dia 05 de abril de 2017 com extensão prevista até dia 05 de agosto de 2017, no entanto, após grande sucesso de público e de crítica - com direito a uma série de prêmios de variadas naturezas - o projeto ficou disponível até dia 31 de dezembro de 2017.

Optou-se por escolher o projeto A Voz da Arte como caso para analisar a interação junto ao visitante, por conta de uma série de fatores. Primeiramente, as duas instituições: IBM - uma das maiores empresas de tecnologia do mundo - e Pinacoteca de São Paulo, um dos mais importantes museus de arte do Brasil - são exemplos notórios de suas áreas, sendo importante gerar uma reflexão acerca de suas ações culturais. Em segundo lugar, utilizar da IA como guia em museus a partir de um estímulo verbal do próprio visitante é uma ação inovadora, que, segundo o levantamento realizado pelos autores deste artigo e também pela própria IBM, ainda não havia sido executada nestas proporções, e de forma aberta ao público, em nenhum outro museu. Por esta questão viu-se também a oportunidade de observar que aspectos específicos destas características de interação podem contribuir para projetos vindouros desta natureza. Por fim, tanto a IBM, como a Pinacoteca, foram instituições que se mostraram abertas e disponíveis aos pesquisadores, permitindo que os devidos materiais pudessem ser coletados dentro do rigor metodológico almejado.

Durante a fase de elaboração da forma de coleta desta pesquisa realizou-se entrevistas com alguns integrantes do processo de desenvolvimento do projeto, entre eles está a Adriana Krohling Kunsch, a qual ocupa a função de 
analista de comunicação e marketing da Pinacoteca. Durante tal depoimento ela informou que a ideia surgiu da própria IBM, com o intuito de aplicar sua tecnologia do Watson - o qual é utilizado em ambientes hospitalares, bancários, administrativos, entre outros - em um espaço diferenciado do habitual, se aproximando de um público não acostumado com o uso desta tecnologia. Por este motivo eles optaram por propor tal experimento em um museu, e por situá-lo dentro da realidade brasileira, país em que $72 \%$ da população nunca esteve em um museu ou instituição cultural (Ogilvy et al., 2017, 0:12). Por estes motivos eles optaram por convidar a Pinacoteca para esta ação conjunta, a qual prontamente se dispôs a participar, e foi responsável pela escolha das obras e também das perguntas e respostas iniciais fornecidas ao Watson.

Iniciou-se, então, o processo de escolha das obras que fariam parte da experiência, selecionadas a partir de um critério de relevância para a história da arte brasileira. As obras foram: Ventania (1888), de Antônio Parreiras; Saudade (1899), de Almeida Junior; São Paulo (1924), de Tarsila do Amaral; Bananal, de Lasar Segall (1927); Mestiço (1934), de Cândido Portinari; Lindonéia a Gioconda do subúrbio (1966), de Rubens Gerchman e O Porco (1967), de Nelson Leirner.

O sistema Watson funciona a partir de um sistema cognitivo respondedor de perguntas (QA-Question Answer) associado a um dispositivo de geolocalização para ambientes fechados, chamado Beacon. O participante pode manifestar-se por meio de voz ou texto, que são interpretados pelo Watson, sendo este um sistema cognitivo de inteligência artificial desenvolvido pela IBM para potencializar a interação entre pessoas e computadores. Este é capaz de responder perguntas em linguagem natural, e é treinado para ser de domínio aberto, possibilitando novos usos e experimentações futuras de pesquisa. O Watson interpreta os dados a partir das variáveis de contexto, como palavras-chave dentre outros parâmetros, e lança a resposta cadastrada que melhor se adapte a pergunta (Toshniwal et al., 2015).

No caso do projeto $A$ Voz da Arte o Watson possui voz feminina, e está, segundo a IBM, há aproximadamente dois anos, "aprendendo" a falar português por meio de ações de bancos financeiros para o uso da interface com intuito de agilizar seus processos (Montarroios, 2017). Segundo informações coletadas em entrevista junto a Paulo Vicelli - diretor de relações institucionais e captação de patrocínio da Pinacoteca - o grupo para qual as respostas foram direcionadas, muito pelo linguajar e expressões utilizadas pela voz do Watson, foi de jovens e adultos. A maior aceitação e engajamento, entretanto, veio das crianças, as quais sentiram-se em liberdade para fazer perguntas de diversas naturezas, sem encontrar barreiras ou limites que as envergonhassem. A obra O Porco, por exemplo, foi a que, segundo ele, obteve maior sucesso entre os mais novos, pois esta abre espaço para a realização de perguntas que fugiam do padrão tradicional.

O projeto foi, portanto, aberto ao público com já um grande número de respostas para cada obra. Quando o aplicativo não consegue encontrar um retorno compatível a pergunta realizada pelo visitante, é gerada uma mensagem: "Desculpe, não sei responder a essa pergunta. Obrigado por ajudar a treinar o Watson". Desta forma tal questão é enviada para um grupo especializado que cadastra as novas informações. Inicialmente esta ação estava funcionando bem, no entanto, pelo volume de visitantes ter superado os valores iniciais planejados, e por não haver uma equipe numerosa que fizesse essa alimentação de dados, não foi possível criar uma rotatividade de novas informações, permanecendo muitas perguntas ainda a serem respondidas até o momento de realização da coleta dos dados aqui apresentados. Além disso, foi também desenvolvido um sistema de like e dislike, a fim de permitir que o usuário tenha a opção de dizer se a resposta foi satisfatória, caso contrário, a pergunta é também enviada ao grupo de cadastro. A IBM disponibilizou trinta aparelhos celulares do tipo iphone 7nos quais o aplicativo estava instalado - acompanhados de fones de ouvido. O visitante, ao entrar no museu, optando por participar da experiência, deixava um documento e assinava um termo de recebimento do equipamento. A partir disso ele poderia permanecer com o dispositivo junto ao corpo ao longo de todo o passeio no museu. Ao passar próximo de uma obra com essa opção de interação, por meio do dispositivo de presença beacon, seria avisado que poderia dar inicio as perguntas.

\subsection{REFERENCIAL TEÓRICO}

Conforme supracitado, este artigo se baseia em uma análise da interação dos visitantes da Pinacoteca, para isso buscou-se embasamento em uma teoria que pudesse dar um direcionamento na coleta e organização dos dados. Pensar em direcionamento de projeto focado nas atividades desempenhadas é o foco do design centrado na atividade, cuja fundamentação teórica se dá na Teoria da Atividade (TA) (Gay e Hembrooke, 2004). Esta teoria tem suas raízes na psicologia históricocultural, a partir dos pensadores russos das décadas de 1920 e 1930, cujas ideias em geral entendiam que a mente humana é fundamentada a partir da interação entre o ser humano e o mundo. Baseado nas teorias de Vygotsky e Leont'ev, a TA tem sua ênfase na construção de significado pela ação, a conexão entre o individual e o social, e o papel de ferramentas mediadoras para 0 desenvolvimento da experiência plena de atividade. Kari

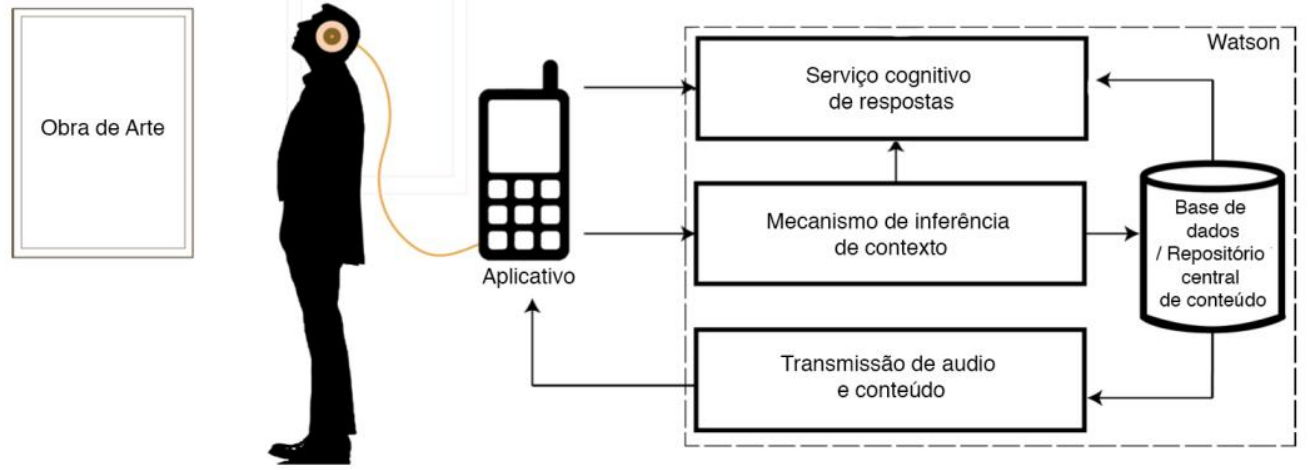

Figura 1: Representação do sistema do Watson na $A$ Voz da Arte. Imagem adaptada da representação do aplicativo Usher do artigo de Toshniwal (2015). 
Kuutti descreve a TA como "uma estrutura filosófica e transdisciplinar de estudar diferentes formas de práticas humanas e processos de desenvolvimento, estando o individuo e o social interconectados ao mesmo tempo" (Kuutti, 1996, p.14). Esta teoria vê a atividade inserida em seu contexto social, ambiental, gestual, e, considera esses elementos como relevantes no processo de leitura de uma ação humana, sendo usada no design para o processo de avaliação de uma interface ou dispositivo.

Avaliar o uso de ferramentas e artefatos se estrutura a partir do conceito de Vygotsky (1984) de mediação, pelo qual esta teoria fundamenta o aprendizado humano. Nela se assume que o sujeito não interage diretamente com o ambiente, e utiliza de ferramentas e símbolos para mediar essa relação (Greenhow e Belbas, 2007), os quais, assim como a linguagem, servem como ferramentas no desenvolvimento da mente e pensamento. A TA oferece uma série de conceitos para melhor descrição e entendimento da atividade, de forma a pensar não só em sistemas utilizáveis, como também, efetivamente úteis para o desenvolvimento de quem os usa (Kaptelinin e Nardi, 2006).

Leont'ev (1981) apoiado nas descobertas de Vygotsky, desenvolve o modelo da atividade em 3 níveis - sujeito, objeto e ferramenta - os quais articulam o aspecto social do indivíduo em atividade com os aspectos internos de sua estrutura cognitiva. Nos fundamentos básicos da atividade humana está o objeto, ou motivo da ação. Engeström (1999) já desenvolve tal modelo partindo para uma atenção mais ampla da atividade (macro) associada a uma perspectiva mais específica (micro), voltada para o sujeito. Essa contribuição destaca a importância da construção de conhecimento por meio da participação em atividades conjuntas e colaborativas. Sua definição de sistema de atividade é "uma atividade humana orientada ao objeto, coletiva e culturalmente mediada" (Engeström et al., 1999, p.9). Com essa contribuição Engeström traz uma evolução do modelo da atividade em forma de triangulo expandido, no qual ele inclui a comunidade (ou contexto social) e outros mediadores da atividade humana: ferramentas, regras e divisão de trabalho. Essa identificação dos diferentes componentes de uma atividade oferece um guia para interpretar contextos complexos, bem como, identifica as diferentes mediações envolvidas, e como essas ações, conscientes e inconscientes, se relacionam entre si. Daí o motivo das setas bidirecionais da figura 2, indicando as múltiplas relações mediadas em um sistema integrado (Gay e Hembrooke, 2004).

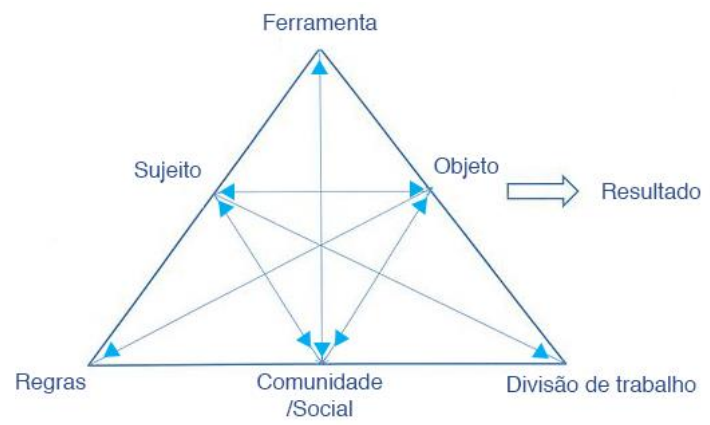

Figura 2: Triângulo de análise de atividade e mediações de Engeström. Fonte: (Gay e Hembrooke, 2004).
A TA tem diversas aplicações, desde estudar o design de sistemas digitais, de práticas de trabalhos em equipe, bom como analisar aprendizado em diversos níveis educacionais (Gay e Hembrooke, 2004). A TA tem sido bastante usada para o estudo do sujeito de sua relação com artefatos tecnológicos digitais. Uma das linhas que estudam esta vertente do design é a interação humanocomputador (IHC), da qual a TA se diferencia em alguns pontos-chave. A IHC se preocupa com o aspecto individual da cognição, sem, muitas vezes, relacioná-lo com os aspectos ambientais e sociais da mente humana (Kaptelinin e Nardi, 2006). Já a TA traz o conceito da "cognição distribuída" o qual permite uma perspectiva diferenciada neste sentido, em que a pessoa não só aprende por meio de uma atividade person-solo, como também por meio de um sistema de fatores interrelacionados das atividades person-plus (Heath et al., 2000). Dá-se, portanto, um espaço maior para o estudo das relações sociais na interação com artefatos, valorizando sua importância para o desenvolvimento cognitivo do ser humano.

Segundo Mwanza (2002) tal teoria não oferece técnicas e procedimentos padronizados de pesquisa. É um instrumento em evolução que disponibiliza guias gerais para analisar a atividade humana em contexto. Para isso ela possui diversos conceitos complexos, direcionados inclusive para o entendimento de setores sociais de maior escala. É importante novamente ressaltar que este artigo é focado no processo de construção de conhecimento presente em uma pequena escala, baseado na interação de visitantes com uma interface tecnológica em um museu. Como caminho, se discute as possíveis contribuições para o design que conceitos presentes nesta teoria podem ter para um maior entendimento do aprendizado humano a partir da interação com mediadores tecnológicos sustentados por inteligência artificial. Optou-se por estruturar a análise dos dados permeada a conceitos da TA, sendo, portanto, uma categorização teórica com o objetivo de melhor estruturar os dados coletados e melhor transmitir os resultados obtidos na pesquisa.

\subsection{LEVANTAMENTO DE DADOS}

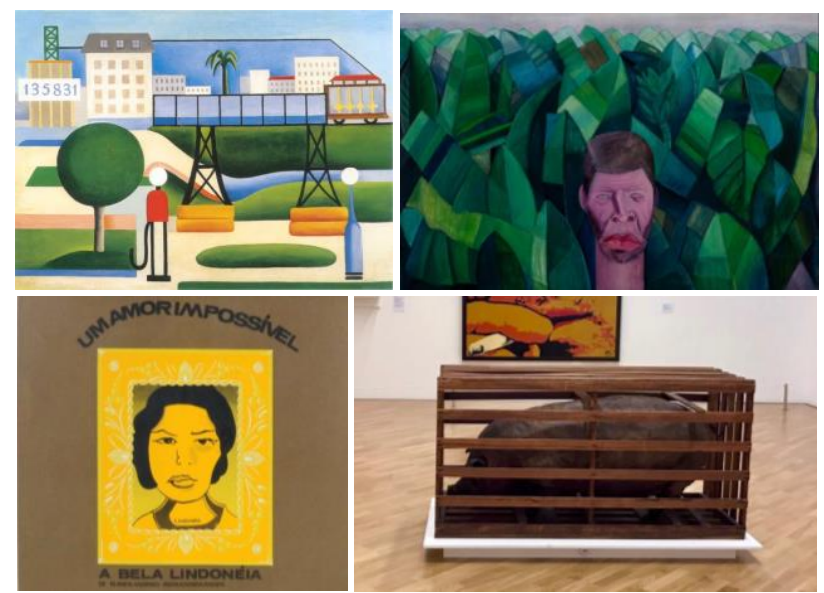

Figura 3, 4, 5 e 6: Fotos relativas as quatro obras analisadas. Respectivamente São Paulo, Bananal, Lindonéia e O Porco.

Para levantamento dos dados deste trabalho, optou-se por selecionar quatro das sete obras disponíveis. Sendo estas: São Paulo (1924), de Tarsila do Amaral (figura 3) e 
Bananal (1927) de Lasar Segall (figura 4) ambas localizadas na galeria José e Paulina Nemirovsky, e Lindonéia a Gioconda do subúrbio (1966) de Rubens Gerchman (figura 5) e O Porco (1967), de Nelson Leirner (figura 6) ambas da galeria Roger Wright. Realizou-se uma coleta focada em 15 visitantes selecionados visando obter uma heterogeneidade da amostra.

A seguir apresenta-se um resumo dos dados básicos coletados junto aos 15 visitantes. Visitante 01 (V1), mulher, 34 anos, jornalista e pós-graduada; V2, homem, 28 anos, coordenador de Tl; V3, menino, 10 anos, estudante, fundamental incompleto; V4, mulher, 44 anos, advogada, pós-graduada; V5, mulher, 79 anos, secretária executiva; V6, menina, 10 anos, estudante, fundamental incompleto; V7, homem, 27 anos, auditor, pós-graduado; V8, mulher, 27 anos, médica, pós-graduada; V9, homem, 23 anos, dentista, superior incompleto; V10, mulher, 31 anos, psicóloga, nível superior completo; V11, menina, 9 anos, estudante, fundamental incompleto; V12, homem, 19 anos, estudante, superior incompleto; V13, homem, 30 anos, web designer, superior completo; V14, mulher, 72 anos, psicóloga, pós-graduada; V15, menina, 11 anos, estudante, fundamental incompleto. Com diferentes faixas-etárias e graus de escolaridade, os visitantes tiveram sua interação coletada por meio de vídeo, feito em uma câmera comum de celular por exigência da própria Pinacoteca em não se utilizar de aparelhagens profissionais. Para coletar as perguntas, e também possibilitar filmagem a distância, foi posicionado um fone bluetooth em volta do pescoço do participante. Já para a coleta das respostas, foi utilizado um gravador digital acoplado ao dispositivo existente. Desta forma os dados básicos da interação puderam ser coletados e armazenados para possibilitar melhor análise futura.

Após a interação, se realizou entrevistas semiestruturadas com cada um dos participantes, nas quais também foi feito uso das imagens das obras impressas visando estimular a memória dos participantes a respeito da experiência. Nestas foram colhidos dados básicos, e foram realizadas perguntas relativas a aspectos que motivaram as indagações às obras, bem como, a questões específicas da própria experiência do visitante. Com essas entrevistas, as quais duraram uma média de 10 a 15 minutos, teve-se a intenção de colher dados mais objetivos das características dos usuários, bem como aspectos subjetivos que não puderam ser observados na interação por meio da filmagem. Vale ressaltar que todos os dados colhidos nesta pesquisa foram feitos mediante autorização do participante por meio da assinatura de um termo de consentimento de uso imagem e áudio. A seguir será introduzida a análise dos dados frutos da observação de gestos, interações sociais e do material levantado nas entrevistas realizadas com os quinze participantes.

\section{RESULTADOS}

Aproxima-se da realização do objetivo deste trabalho a partir de uma classificação de diretrizes projetuais fundamentadas na TA voltadas a entender como ocorre a construção de conhecimento do visitante em interação com o projeto $A$ Voz da Arte. Tais diretrizes são apresentadas abaixo destacando-as em conjunto com exemplos observados na coleta e análise dos dados junto aos visitantes. Tal análise estruturou-se com base nos gestos e interações sociais apresentados pelos 15 participantes em interação com as quatro obras do museu. Buscou-se também considerar o momento e a sequência que tais interações aconteceram, levando em consideração as características básicas do visitante, bem como, o contexto social e ambiental da atividade em conjunto com a própria opinião dos visitantes manifestada nas entrevistas. Vale ressaltar que se provou muito importante que tenha sido feita uma análise das respostas dadas pelo Watson em conjunto com as reações corporais e sociais que os visitantes tiveram a elas. O fato de haver sido feito um registro em vídeo facilitou para a análise detalhada destas reações. Notouse quatro conceitos da TA predominantes que serviram de base para estruturar os dados, os quais são abaixo destacados.

\subsection{TRANSPARÊNCIA}

Sendo tradicionalmente considerado um aspecto chave da qualidade de uma interface, a transparência descreve a capacidade de um artefato de captar o mínimo possível da atenção do usuário, isto é, ser, metaforicamente, "invisível" (Kaptelinin e Nardi, 2006). A transparência, portanto, não é uma característica que pode ser embutida no projeto de um sistema, e sim deve-se projetar condições para que tais conceito ocorra. O aplicativo projetado para acompanhar o processo de uso da experiência $A$ Voz da Arte pode ser considerado um projeto em que o nível de transparência foi bem pensado, ainda assim, no item seguinte, aponta-se melhoras possíveis que o deixariam, ao ver do pesquisador, ainda melhor. A sua interface simples, apresenta um sistema de ações objetivo e apresentado de forma clara, a qual funciona de forma muito assemelhada aos programas de mensagem de áudio do celular, como whatsapp, por exemplo, nos quais há um ícone de microfone que, quando pressionado, inicia o processo de gravação da pergunta. Após o término desta, depois de alguns breves segundos de carregamento, é dado a resposta que, em teoria, atende a dúvida do visitante. Durante a transmissão do áudio, o círculo central pulsa, aumentando e diminuindo sua luminosidade.

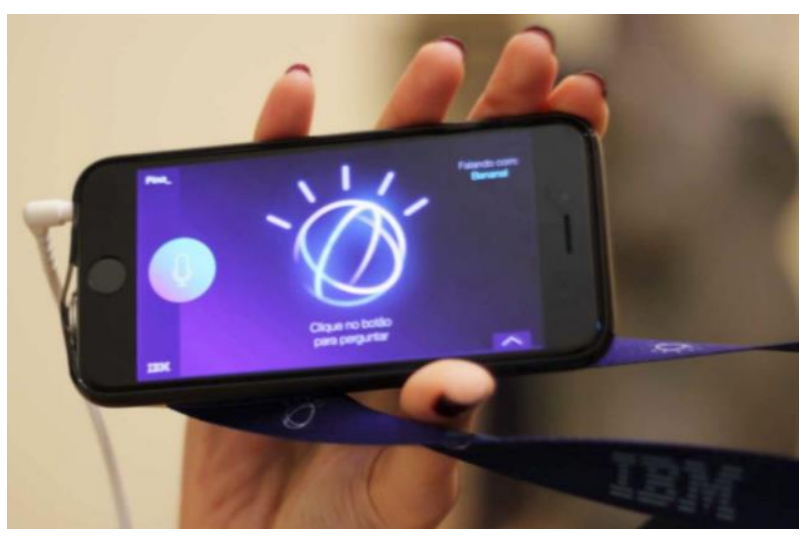

Figura 7: Foto retirada da tela padrão do aplicativo. Fonte: <http://amikku.com/2017/04/12/pinacotecasp/>

O conceito de transparência é para a $\mathrm{HCl}$, um aspecto fundamental da qualidade de uma interface. Tipicamente ele é descrito como a possibilidade de deixar a interface projetada de forma que chame o mínimo de atenção do usuário além das funções básicas necessárias para seu uso, isto é, que ele não tenha a necessidade de notar constantemente o sistema (Kaptelinin e Nardi, 2006). 
Donald Norman (2018), defende também a importância de tornar os feedbacks visíveis na execução de uma ação, para que as pessoas possam saber os efeitos de suas interações. Esta capacidade de resposta de um sistema também compreende o sentido de transparência ao fazer com que a interface mostre os resultados, erros e acertos da ação humana. A tecnologia pode servir como meio para tornar visível o que de outro modo seria invisível melhorando o feedback e a capacidade do usuário de manter o controle. Segundo o autor, devemos projetar para o erro, identificando os prováveis deslizes dentro da interação, para minimizá-los ao máximo (Norman, 2018).

Os problemas identificados no processo de reposta se deram muito por conta das limitações tecnológicas vigentes, entretanto, cabe deixar aqui registrado o que foi manifestado como sugestões pelos próprios usuários. Em entrevista, quando perguntado qual ponto incomodou, e o que eles teriam como sugestão para melhora do projeto, um ponto que se repetiu em muitos casos foi 0 lançamento de respostas repetidas para perguntas distintas. Quando isso ocorria, muitas das vezes, o visitante desconhecia a possibilidade de "pular" a resposta replicada - mesmo tendo sido uma função apresentada pelo monitor da experiência ao entregar o celular ao visitante - e ouvia toda a resposta novamente. Como exemplo, no quadro 1 apresenta-se alguns casos selecionados em que o Watson identificou, para distintas perguntas, a mesma reposta, a qual o participante ouviu integralmente. Os dados sugerem que, por ter sido manifestado muitas vezes por distintos visitantes na entrevista, esse foi um aspecto que realmente incomodou a experiência de visitação dos mesmos. Uma solução possível seria haver um registro por participante das respostas já enviadas, para que não fosse permitido a repetição destas. Outra solução seria deixar mais transparente a possibilidade de "pular" as respostas, já que este foi um comando que foi utilizado apenas por 1 dos 15 participantes observados.

Quadro 1 - Visitante 11 - Perguntas relativas a obra Bananal, de Lasar Segall (1927).

\begin{tabular}{|l|l|}
\hline Pergunta & Resposta \\
\hline $\begin{array}{l}\text { Qual é a } \\
\text { representaçã } \\
\text { o dessa } \\
\text { pessoa? }\end{array}$ & $\begin{array}{l}\text { Essa obra de Seagal é representativa de } \\
\text { sua preocupação em retratar a agonia } \\
\text { social e psicológica sofrida pelo povo negro } \\
\text { no Brasil. Ao pintá-la ele afirmou estar se } \\
\text { sentindo como um membro da população } \\
\text { negra, isolado e sozinho, sem respaldo do } \\
\text { poder público e sem uma interação com os } \\
\text { vizinhos do bairro em que vivia. }\end{array}$ \\
\hline $\begin{array}{l}\text { Como foi que } \\
\text { os escravos } \\
\text { chegaram ao } \\
\text { brasil? }\end{array}$ & $\begin{array}{l}\text { Essa obra de Seagal é representativa... } \\
\text { (repetição da resposta anterior). }\end{array}$ \\
\hline
\end{tabular}

\subsection{FERRAMENTA}

Segundo Greenhow e Belbas (2007), o sujeito não interage diretamente com o ambiente, ele utiliza de ferramentas e símbolos para mediar essa relação, os quais servem como ferramentas no desenvolvimento da mente. A TA também apresenta pontos importantes para entender o papel dos artefatos para o aprendizado humano em variados contextos. Um ponto fundamental de seu embasamento define o aprendizado como oriundo de uma relação entre sujeito (aprendiz), um objeto (tarefa, atividade, conteúdo a ser aprendido) e um artefato mediador (uma ferramenta, um computador, leis). Tal questão nos coloca dentro da própria noção do uso de instrumentos para estimular esta relação dos seres humanos com o mundo, o uso de artefatos como elementos utilizados para potencializar o desenvolvimento da mente, a construção de conhecimento. Inúmeros artefatos foram desenvolvidos para mediar nossa relação com o mundo, e é possível inferir que novas e distintas formas de transmissão de conteúdo podem ser uma forma de tornar o caminho entre conteúdo e visitante mais facilmente cruzável.

O projeto $A$ Voz da Arte torna-se relevante para ser pesquisado pois nele a atividade do visitante se realiza por meio de duas ferramentas. A primeira é o celular, o qual serve de suporte para o principal meio de interação, que é a voz, elaborada tanto de forma analógica (visitante), como virtual (Watson). Por sua característica invisível, a linguagem serve diretamente de ferramenta que interage em conjunto com o aplicativo, não sendo este um objeto de atividade, e sim um artefato de mediação. As pessoas, portanto, não interagem pela voz com o aplicativo em si, e sim interagem com o mundo mediados pelo aplicativo. A própria voz é a ferramenta que se liga aos diferentes mediadores na construção de conhecimento pela interação. No caso da atividade com o Watson, por meio interface do aplicativo da $A$ Voz da Arte, o visitante tem a IA como ferramenta para chegar no conhecimento da obra de arte, que é o objeto que motiva a sua ação.

Em se tratando do uso das ferramentas, o sistema proposto pela IBM e Pinacoteca, como dito acima, consiste em um conjunto de aparelho celular e fones de ouvido. A interface do celular não apresenta nenhum conteúdo específico durante a resposta do Watson - com exceção da interação opcional por escrito, para pessoas com problemas auditivos, a qual não fez parte dos casos coletados neste artigo. Em alguns gestos dos participantes, foi observado um movimento constante de olhar para o visor do celular durante a resposta, mesmo ali não havendo nenhuma informação a ser mostrada, sendo todas estas transmitidas por meio de voz, como pode ser visto na figura 8 referente a interação do Visitante 2. Isso ocorreu de tal forma que muitos participantes só chegavam a olhar para a obra durante a pergunta, e durante a resposta. Em especial quando estas eram longas, os usuários realizavam movimentos corporais repetitivos, muitas vezes olhando para a tela do celular. Este dado sugere uma certa impaciência por parte dos visitantes com respostas de maior duração. Mostra também a necessidade, por parte dos visitantes, para com a visualização de um objeto mediador a ser manipulado, já que a mera imagem da tela do aplicativo chama mais a atenção do que a obra em si. Pode-se inferir que uma solução possível é tornar a tela do celular, apresentado na figura 7, ainda mais invisível durante a resposta. A pulsação de luz, realizada durante a transmissão do áudio da resposta, poderia ser mais discreta, melhorando ainda mais este quesito da visitação, entendendo que sua existência é importante no sentido de um feedback visual ao usuário. 


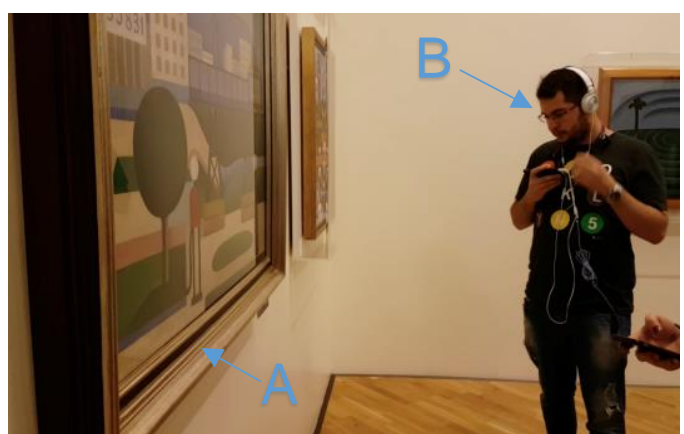

Figura 8: Foto demonstrando Visitante 2 muitas vezes olhando para o celular durante a resposta. A: obra, B: V2. Fonte: Acervo dos autores.

O objetivo do design deve ser prover uma integração ótima entre objetos de domínio e instrumentos de interação (Kaptelinin e Nardi, 2006). Dentro do sentido do uso da ferramenta no sentido digital, identificou-se um alto número de registros inválidos do entendimento da pergunta pela IA, ou seja, um índice alto de IDK ( / don't know). Observou-se também um baixo índice de tentativas em refazer a pergunta de outra forma, a fim de utilizar diferentes palavras-chave para o entendimento da pergunta por parte do Watson. Esses dados sugerem um certo contentamento com informações medianamente corretas, por parte dos visitantes, com respostas que não tinham em seu conteúdo as informações ali solicitadas. Exemplos disso, escolhidos dentre muitos outros, destacam-se no quadro 02, apresentada a seguir.

Quadro 2 - Visitante 01 e 04 - Perguntas selecionadas.

\begin{tabular}{|c|c|c|}
\hline Visitante & Pergunta & Resposta \\
\hline $\begin{array}{l}\text { V1 à obra } O \\
\text { Porco de } \\
\text { Nelson Leirner } \\
(1967) .\end{array}$ & $\begin{array}{l}\text { Esse porco também } \\
\text { é acervo da } \\
\text { Pinacoteca ou é de } \\
\text { alguma exposição } \\
\text { que também... roda } \\
\text { o país? }\end{array}$ & $\begin{array}{l}\text { O Porco foi criado } \\
\text { no ateliê do } \\
\text { próprio artista, que } \\
\text { ficava aqui mesmo } \\
\text { em São Paulo. }\end{array}$ \\
\hline $\begin{array}{l}\text { V1 à Lindonéia, } \\
\text { de Rubens } \\
\text { Gerchman } \\
\text { (1966). }\end{array}$ & $\begin{array}{l}\text { Qual técnica } \\
\text { utilizada por ele? }\end{array}$ & $\begin{array}{l}\text { Lindonéia é uma } \\
\text { personagem } \\
\text { fictícia, criada a } \\
\text { partir da } \\
\text { imaginação do } \\
\text { autor. }\end{array}$ \\
\hline $\begin{array}{l}\text { V4 à Lindonéia, } \\
\text { de Rubens } \\
\text { Gerchman } \\
(1966) .\end{array}$ & $\begin{array}{l}\text { Em que ano você } \\
\text { morreu? }\end{array}$ & $\begin{array}{l}\text { O texto na obra } \\
\text { sugere que } \\
\text { Lindonéia morreu } \\
\text { jovem, aos } 18 \\
\text { anos de idade. }\end{array}$ \\
\hline
\end{tabular}

\subsection{AFFORDANCE}

Um conceito análogo que também vale ser aqui ressaltado é o affordance, sendo este muito discutido quando se trata do design centrado no usuário. A TA tem também alguns trabalhos tratando deste tema, o qual consiste em uma forma de entender melhor a interface e a relação humana com objetos (Kaptelin e Nardi, 2006; Gay e Hembrooke, 2004). O termo affordance foi trazido originalmente por Gibson (1979), ao estudar a percepção visual dos seres humanos. Para ele, o ambiente fornece elementos para que os animais interajam com ele, e estes elementos são chamados de affordance. Tal conceito é trazido para a $\mathrm{HCl}$ por Donald Norman, e foi amplamente discutido ao longo dos anos. Para Norman
(1988), affordances são as possibilidades de ação fornecidas pelo ambiente, servindo como uma ferramenta que proporciona fortes pistas visuais para a operação das coisas. Objetos possuem, portanto, propriedades de como estes podem ser utilizados, as quais podem ser percebidas. "Os botões são para apertar. As maçanetas são para girar. Os entalhes são para introduzir coisas dentro. Bolas são para jogar ou saltar." (Norman, 1988, p.9). Desta forma, conhecer estas possibilidades é dar aos seres humanos, por meio do projeto, a capacidade de melhor interagir com o ambiente e com os artefatos ao seu redor.

Segundo Kaptelinin e Nardi (2006), pesquisas recentes revelam que usuários raramente costumam operar objetos de interesse diretamente. Tanto em ambientes físicos como virtuais se faz uso de instrumentos para realizar operação em artefatos. Para colocar um parafuso em um pedaço de madeira, ninguém utiliza apenas as mãos, e sim utiliza-se uma chave de fenda para realizar o efeito desejado. Digitalmente também se utiliza de uma barra de rolagem para subir ou baixar a leitura de um documento. Neste caso, o objeto de domínio é o texto, e 0 ato de mover a barra de rolagem é um instrumento de interação (Kaptelinin e Nardi, 2006).

Notou-se em muitas das interações observadas - mais especificamente nas das visitantes 05 e 14, as quais eram de idade mais avançada - uma deficiência em dar elementos para que a interação destes fosse mais assertiva com relação a obra que faz parte do projeto. Notou-se essa questão em muitos momentos em que os participantes se direcionavam a outras obras que não estavam inclusas na experiência. Houve casos inclusive de perguntas serem realizadas de forma errônea a obras aleatórias do acervo. Isso ocorre porque o localizador beacon reconhece a posição do visitante por proximidade, e consequentemente não identifica o seu direcionamento. Quando há obras muito próximas, o erro de direção não é identificado e acusado pelo sistema, conforme pode ser exemplificado na figura 9, na qual a visitante 05 está marcada como $B$. Ao identificar que esta chegou na arte cadastrada na experiência, era apresentada uma imagem pequena da obra na tela do celular. Esta, entretanto, por si só não transmitiu a mensagem de que a obra participante era O Porco, situada no centro da sala. Entende-se que uma solução possível para esta falha de affordance seja deixar mais visível a obra para qual as perguntas são direcionadas, aumentando a imagem e deixando-a na tela do aplicativo por mais tempo, bem como colocar sinalizadores físicos mais visíveis, a fim de deixar a informação das obras participantes mais nítida aos visitantes, em especial aqueles não familiarizados com o uso de smartphones.

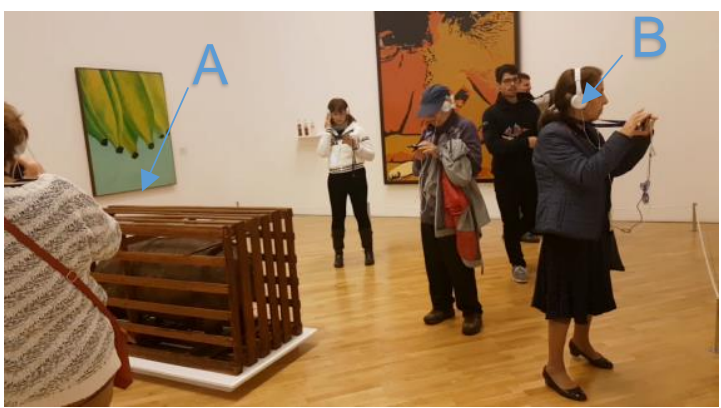

Figura 9: Foto demonstrando erro de direção a obra. A: obra, B: Visitante 5. Fonte: Acervo dos autores. 


\subsection{SOCIABILIDADE}

Um dos pontos relevantes observados é que a interação com o Watson na Pinacoteca se dá de forma prioritariamente individual. $\mathrm{O}$ aplicativo em conjunto com o fone forma um sistema de interação introspectivo, em que o feedback é dado para apenas uma pessoa em específico. Observou-se, entretanto, que muitos visitantes chegaram a ir de encontro a esta característica ao comentar as respostas recebidas e compará-las com os colegas de visitação, além de diversos outros tipos de interações sociais observadas. Em suma, quando houve mais de um participante simultâneo, ocorreram trocas de diálogo de alguma natureza, as quais, no geral se deram com o objetivo de compartilhar a resposta recebida com o colega. Tais questões elencadas suscitam um exame relativo a relevância das interações sociais para 0 aprendizado, e de como as relações entre indivíduos observados contribuíram como elemento potencializador da experiência de visitação.

Uma ideia fundamental da TA é que a mente humana tem sua natureza social. Agimos com ou para, outras pessoas, sejam elas grupos, organizações, comunidades ou culturas. Beetham define aprendizado como uma interação específica entre aprendiz (es) com outro (s) usando ferramentas específicas e recurso orientados a resultados específicos (Beetham, 2013). Para isso focase no contexto e nos relacionamentos, no lugar de preocupar-se exclusivamente com o raciocínio dos indivíduos, considerando o aspecto social, da atividade de interação. Vygotsky sustenta que a cultura e a sociedade não são fatores externos a mente que a influenciam, e sim são elementos diretamente envolvidos na produção da mente. Tal relação da mente humana com o mundo é dividida por ele em duas dimensões: a) interna-externa e b) individual e coletiva (Vygotsky, 1984). Observou-se que, nos casos em que o participante se encontrava só, as reações eram contidas e tímidas, quando comparado com quando este se encontrava em dupla ou grupo, sendo estas realizadas de forma coletiva, mais expressivas. Segundo o pesquisador Dirk Vom Leh, ao realizar extensa pesquisa por vídeo de interações de visitantes em museus, a maneira como o visitante vê e sente o espaço expositivo é diretamente influenciado pela sua interação social. As pessoas compartilham suas experiências com os outros - seja com conhecidos ou não - através de ações verbais ou corporais (Vom Lehn, 2006).

Inspirado nisso, no presente artigo buscou-se interpretar gestos e interações dos visitantes inseridos no contexto em que são estimulados. Notou-se que muitos dos que estavam em grupo repetiam a interação com seu companheiro de visitação. Alguns desses exemplos são apontados abaixo a partir da visitação de V8, junto de sua acompanhante que participou da experiência em conjunto.

Acompanhante V8: Pergunta quem é esse homem! V8: Quem é esse homem?

(Perguntou sem apertar o botão de gravar pergunta).

(Sem resposta elas olham para o celular e entendem o que devem fazer. V1 finalmente encontra o botão e pergunta)

V8: Quem é esse homem?

Watson: Essa imagem representa o Olegário, um senhor negro e idoso que fora escravo na fazenda de amigos do artista.

Acompanhante: Ouviu?

\section{V8: Ouvi!}

A sugestão da pergunta vir de um acompanhante também realizando a experiência ocorreu em muitos dos casos observados. Além disso houve também reações as repostas, como risadas e comentários relativos a uma certa surpresa com relação a resposta recebida. Isso se apresenta abaixo no caso novamente observado na interação da acompanhante da V8.

Acompanhante V8: Porque é um amor impossível? (Voltando-se a V8)

Watson: Não sabemos quem amava Lindonéia, ou quem ela amava a partir da observação dessa obra. Mas, pode ser que o amor seja impossível porque Lindonéia está morta. Acompanhante V8: Ah, adorei, (risos) o amor é impossível porque Lindonéia está morta. Adorei (risos)!

Isso também se apresenta no exemplo abaixo, realizado durante a experiência do V2, o qual foi acompanhado de sua esposa, a qual também participou da experiência. Nesta interação ele faz uma pergunta relativa a comparação da obra com uma personagem de um desenho infantil, a qual também é um porco.

Quadro 3 - Visitante 2 - Perguntas relativas a obra O Porco.

\begin{tabular}{|l|l|l|}
\hline Visitante & Pergunta & Resposta \\
\hline $\begin{array}{l}\text { V2 à obra } O \\
\begin{array}{l}\text { Porco de } \\
\text { Nelson Leirner } \\
(1967) .\end{array}\end{array}$ & Você é a PepaPig? & $\begin{array}{l}\text { O Porco não é } \\
\text { amigo da PegaPig, } \\
\text { mas aposto que ele }\end{array}$ \\
\hline
\end{tabular}

Após essa interação V2 sorri para sua esposa balançando afirmativamente a cabeça e os dois riem da resposta dada pelo Watson. Em outro momento da visita de ambos, ocorre a seguinte interação.

Esposa V2: ....adorei a resposta

(Rindo bastante)

V2: $O$ que foi?

Esposa V2: (retirando o fone de ouvido) Eu perguntei qual o valor da obra.

V2: Ela falou que é inestimável...um valor inestimável.

Esposa V2: É... Muito legal!

(Rindo novamente em conjunto)

Tais relações acompanhadas na visita demonstram que o contato social provoca dinamismo e também risos dos participantes ao compartilharem suas respostas e interações em conjunto. Além dos aspectos acima citados, existe também o aspecto social contribuindo por meio de uma relação de troca entre os usuários. Isso é tratado por Vygotsky ao defender a importância da presença de um mentor mais experiente para o processo de aprendizado. Algo, ou alguém, que tenha mais informações, e que seja o meio de transmissão do conhecimento (Vygotsky, 1984). Não necessariamente a posição do mentor precisa ser ocupada por um outro ser humano, como é o caso da experiência com o Watson, no qual a própria voz virtual pode suprir este quesito de ser o vetor da transmissão de conteúdo. Entende-se, entretanto, que, como defende Vygotsky, as relações sociais entre visitantes devem ser fomentadas. O projeto da interface poderia permitir que dois ou mais participantes pudessem compartilhar da mesma experiência em conjunto. Tal modificação no projeto poderia ser de natureza simples - como um splitter de entrada de fones de ouvido por exemplo - mas que 
poderia gerar uma rica contribuição para as interações realizadas no museu.

Durante o processo de observação da interação dos visitantes houve, em muitos casos, interações em duplas. Nestas foi percebido que os participantes costumeiramente coordenavam suas ações em conformidade com seus pares. Em dois dos casos observados eram pais em conjunto com seus filhos. No primeiro, o V4, uma mulher, estava acompanhado de seu filho. Enquanto ela estava na atividade, o filho também participava, e constantemente buscava interrompê-la para tratar de alguma resposta que Ihe chamou a atenção. Notou-se que o fato da experiência com o Watson se dar de forma individual, ainda somado ao uso de fones grandes que isolam as interferências externas, fez com que muitas de suas interações sociais fossem prejudicadas. No segundo caso apenas V11 foi a que participou, sua mãe ficava ao seu lado enquanto a interação acontecia. Esse caso foi especialmente interessante porque a mãe, ao invés de dar perguntas prontas para a filha reproduzir - o que ocorreu em alguns casos observados - utilizou do Watson como ferramenta para fazer a filha pensar e criar seus próprios questionamentos. Este último caso é apontado abaixo como exemplo, como V11, interagindo com sua mãe a respeito da obra Bananal, de Lasar Segall.

V11: Essa pintura é da imaginação dele ou é algum lugar que ele visitou?

Watson: Desculpe, isso eu não sei responder. Obrigada por treinar o Watson.

V11: (voltando-se para a mãe) Apareceu assim: "desculpe essa eu não sei responder" (as duas dão gargalhadas juntas e ficam alguns segundos olhando a obra) Mãe V11: E o que foi que te chamou a atenção na obra? V11: (automaticamente repetindo o que a mãe falou, só que em forma de pergunta) $\mathrm{O}$ que foi que te chamou a aten... (interrompida pela mãe V11 ri novamente)

Mãe V11: Não...era pra você...o que te chamou a atenção na obra.

V11: Ah, o homem, né?

Mãe V11: Ele te explicou o que que é?

V11: Negro que tá isolado, sozinho, sem ninguém ... escravizado.

Mãe V11: hummm...ah que legal! (Acenando positivamente com a cabeça).

Notou-se, portanto, que a mãe serviu de instrumento para que V11 fizesse uma análise do que mais havia gostado, e que resposta foi mais interessante, fazendo-a repetir, mostrando o que havia aprendido e internalizado com a experiência. Tais dados, em conjunto com os anteriores, sugerem que as interações sociais são importantes para o fomento da experiência interativa, ampliando as possibilidades da construção de conhecimento, podendo contribuir bastante quando utilizado como diretriz projetual em futuras mediações tecnológicas em espaços museológicos. Tendo em vista que a interação com o Watson é prioritariamente individual, ressalta-se a importância de que, em futuras aplicações de mediações desta natureza, possa haver abertura para o uso do aspecto social como diretriz projetual, permitindo interações conjuntas entre dois ou mais usuários.

\section{CONCLUSÃO}

Neste trabalho foi observado que a tecnologia serve de meio potencializador da experiência, entretanto, há elementos humanos que necessitam ser devidamente considerados para uma interação mais fluida que possibilite, de fato, uma construção de conhecimento e um diálogo entre visitante e artefato tecnológico. Observar a ação humana a fundo permitiu que diversos problemas e potencialidades fossem observados a fim de mapear pontos importantes de usabilidade para tornar a experiência de interação melhor para os usuários. Para isso a coleta em vídeo junto aos visitantes foi bastante útil, pois possibilitou que o pesquisador tivesse um maior acesso a gestos e interações sociais presentes no momento da atividade.

Notou-se que a Teoria da Atividade (TA) serviu como uma boa base teórica para dar suporte aos pesquisadores no sentido de termos e conceitos que guiassem o processo de análise dos dados coletados. Assim como afirma Querol, Cassandre e Bulgacov (2014), a TA mostra que aprender não envolve apenas a formação de conceitos teóricos, mas também a sua materialização por meio de artefatos culturais, sejam estes modelos, conceitos ou teorias. Desta forma, a divisão em conceitos de transparência, ferramenta, affordance e sociabilidade apresenta-se com a intenção de classificação dos aspectos relevantes observados. Vale ressaltar que classificar um sistema ou um processo é válido quando visto como modelos a serem, ou não, seguidos a fim de entender melhor um fenômeno. Identificar padrões não deixa de ser uma forma de simplificar um fenômeno real e complexo, cuja natureza precisa ser traduzida, de forma a mapear sua dinâmica, a fim de que possamos entendêlos (Mitchell, 2009).

Sugere-se que a mudança de alguns pontos específicos do projeto de interação junto ao aplicativo pode ser uma contribuição na melhora da usabilidade geral. Tendo em vista que a interação com o Watson é prioritariamente individual, ressalta-se a importância de que, em mediadores de conteúdo desta natureza, possa haver abertura para um maior aproveitamento do aspecto social como diretriz projetual, permitindo interações conjuntas entre dois ou mais usuários em um mesmo dispositivo ou sistema. Este trabalho buscou tratar da construção de conhecimento por meio do uso de tecnologia digital em museus, mais especificamente com o uso de inteligência artificial. Pode-se inferir que os pontos levantados na análise são parte de uma contribuição a cerca do uso de interfaces desta natureza em espaços culturais e artísticos. Ressalta-se também a importância de haver mais trabalhos voltados a análises da usabilidade e compreensibilidade das interfaces propostas nestas instituições, especialmente dentro de um contexto nacional.

\section{AGRADECIMENTOS}

Esta pesquisa é parte da dissertação de mestrado em Design da Faculdade de Arquitetura e Urbanismo da USP do primeiro autor do artigo. Foi financiada pela Coordenação de Aperfeiçoamento de Pessoal de Nível Superior (CAPES). Agradecemos pelo apoio concedido.

\section{REFERÊNCIAS}

BEETHAM, H. Designing for active learning in technology-rich contexts. Rethinking pedagogy for a digital age: Designing for 21st century learning, p. 31-48, 2013. 
BOELTER, V. Design de Exposição na Arte e Tecnologia Digital: uma prática em construção. Estudos em Design, v. 24, n. 3, 2016. ISSN 1983-196X.

ENGESTRÖM, Y.; MIETTINEN, R.; PUNAMÄKI, R.-L. Perspectives on activity theory. Cambridge University Press, 1999. ISBN 052143730X.

GAY, G.; HEMBROOKE, H. Activity-centered design. An Ecological Approac h, 2004.

GIBSON, J. J. The theory of affordances The Ecological Approach to Visual Perception (pp. 127-143): Boston: Houghton Miffin 1979

GREENHOW, C.; BELBAS, B. Using activity-oriented design methods to study collaborative knowledge-building in elearning courses within higher education. International Journal of Computer-Supported Collaborative Learning, v. 2, n. 4, p. 363-391, 2007. ISSN 1556-1607.

HEATH, C.; KNOBLAUCH, H.; LUFF, P. Technology and social interaction: the emergence of 'workplace studies'. The British journal of sociology, v. 51, n. 2, p. 299-320, 2000. ISSN 1468-4446.

KAPTELININ, V.; NARDI, B. A. Acting with technology: Activity theory and interaction design. MIT press, 2006. ISBN 0262112981.

KUUTTI, K. Activity theory as a potential framework for humancomputer interaction research. Context and consciousness: Activity theory and human-computer interaction, v. 17, 1996.

LEONTJEV, A. N. Problems of the development of the mind 1981.

MITCHELL, M. Complexity: A guided tour. Oxford University Press, 2009. ISBN 0199724571.
MONTARROIOS, F. Watson: uma voz para a arte ou uma cara para a tecnologia? , 2017. Disponível em: < https://www.gazetadopovo.com.br/manualdousuario/watsonuma-voz-para-arte-ou-uma-cara-para-tecnologia/ >. Acesso em: 01/06/18.

MWANZA, D. Towards an activity-oriented design method for $\mathrm{HCl}$ research and practice. 2002.

NORMAN, D. The design of everyday things (originally published: The psychology of everyday things). The Design of Everyday Things (Originally published: The psychology of everyday things), v. 20, 1988.

NORMAN, D. A. O design do dia a dia. Editora Rocco, 2018. ISBN 8569474423.

OGILVY; IBM; PINACOTECA. A Voz da Arte - IBM Watson Youtube: 3:31 p. 2017.

QUEROL, M. A. P.; CASSANDRE, M. P.; BULGACOV, Y. L. M. Teoria da Atividade: contribuições conceituais e metodológicas para o estudo da aprendizagem organizacional. Gestão \& Produção, v. 21, n. 2, p. 405-416, 2014-06 2014. ISSN 0104-530X. Disponível em: < http://www.scielo.br/scielo.php?script=sci_arttext\&pid=S0104 $-530 \times 2014000200013\langle=p t>$

TOSHNIWAL, S. et al. USHER: an intelligent tour companion. Proceedings of the 20th International Conference on Intelligent User Interfaces Companion, 2015, ACM, 2015. p.81-84.

VOM LEHN, D. Embodying experience: A video-based examination of visitors' conduct and interaction in museums. European Journal of Marketing, v. 40, n. 11/12, p. 1340 1359, 2006. ISSN 0309-0566.

VYGOTSKY, L. S. A formação social da mente: São Paulo: Martins Fontes 1984 